\title{
Encontro entre pobreza e moral em Luanda. Urbanização, direitos e violência*
}

Daniel dos Santos**

Resumo: $\mathrm{O}$ artigo apresenta uma análise da questão urbana da capital angolana, com base em duas pesquisas feitas ao final dos anos 1980, uma sobre a economia paralela em Angola, mais especificamente em sua capital, Luanda; outra sobre as políticas de urbanização da periferia africana, ao sul do Saara, assim como novas pesquisas realizadas entre 2006 e 2010 voltadas, desta vez, à compreensão da nova realidade, passados 20 anos, e à descrição e análise das mudanças ocorridas, assim como as razões dessas transformações, conforme a narrativa e as práticas dos atores sociais implicados. O texto se concentra na análise do desenvolvimento imobiliário, com a reconstrução da infraestrutura de base destruída durante a guerra civil, destacando reiteradas disputas entre o Estado angolano e as populações de cidadãos deserdados e deslocados pela guerra, vítimas, durante muito tempo, das lutas políticas e da violência das diferentes facções da elite que lutam pelo controle do Estado desde a Independência.

Palavras-chave: pobreza, moral, urbanização, direitos, exclusão social, violência, cidadania.

Pois, em Oran, a pobreza era uma mentalidade, e não uma condição. Eu vi pessoas aconchegadas em moradias mil vezes reformadas, com chinelos rasgados, porém de cabeça erguida. Em Oran, aceitava-se uma vida humilde, jamais submissa Khadra (2013: 78).

Quando estabelecemos contatos sociais, se não conseguimos imaginar nos outros as faculdades interiores de pensar e de sentir, então a democracia há de fracassar, pois ela se fundamenta justamente no respeito e no cuidado com os outros, sentimentos que levam a encará-los como seres humanos, e não como simples objetos Nussbaum (2010: 32).

A esmola, a lavagem de carros e diferentes formas de frete têm sido o ofício de algumas crianças de rua em Luanda. Com o dinheiro arrecadado, fruto de seu esforço, parte vai para a alimentação, parte para vestuário. Contudo, a sorte nem sempre bate à porta. Expostas ao perigo, as crianças enfrentam chuva, frio e fome. Muitas

\author{
* Esta pesquisa \\ abrange um \\ período curto (de \\ 2006 a 2012), que \\ corresponde à \\ primeira fase da \\ nova urbanização \\ da capital angolana. \\ Obviamente, a \\ situação, de certa \\ forma, mudou, pois \\ a construção de \\ moradias "sociais" \\ desenvolveu-se \\ de maneira mais \\ constante. Além \\ do mais, o Estado \\ angolano - criticado \\ e desaprovado pelas \\ classes pobres e as \\ associações civis - \\ procura apresentar \\ uma imagem positiva \\ ao povo angolano. \\ Entretanto, essas \\ políticas não \\ cumprem seus \\ objetivos. Nossas \\ pesquisas continuam \\ com o intuito de \\ destacar as novas \\ lutas urbanas que \\ acontecem em \\ Luanda, assim como \\ as atuais políticas do \\ Estado angolano. \\ Tradução de Bruno \\ Guerard do artigo \\ "Rencontre entre \\ la pauvreté et la \\ morale à Luanda. \\ Urbanisation, droits \\ et violence".

** Criminologia/
Faculdade das
Ciências Sociais,
Universidade de
Ottawa.
<ddsantos@rogers.
com>; <esantos@
uottawa.ca>. \\ ** Criminologia/ \\ Ciências Sociais, \\ Universidade de \\ uottawa.ca>.
}


vezes, o recurso é cheirar gasolina para

enganar o estômago

http://www.angonoticias.com/Artigos/

item/30412 (6 Jun. 2011).

\title{
Introdução
}

\begin{abstract}
O final dos anos 1980, fizemos duas pesquisas, uma sobre a economia paralela em Angola - informal, ilícita, ilegal, de mercado negro, conforme o jargão usado pelos pesquisadores -, com enfoque na capital: Luanda (dos Santos, 1990: 157-174); outra sobre as políticas de urbanização da periferia africana, ao sul do Saara (dos Santos, 1989).
\end{abstract}

Por várias vezes retornamos a Angola - notadamente em 2006, 2007, 2009 e 2010 -, para a realização de novos trabalhos. O objetivo dessas viagens consistia em entender a realidade local e preparar um novo projeto de pesquisa, desta vez exclusivamente focado sobre a cidade de Luanda. Tratava-se de observar a realidade passados mais de 20 anos, descrever e analisar as mudanças ocorridas, assim como os móveis das transformações, conforme a narrativa e as práticas dos atores sociais implicados.

Isso levou a uma primeira comunicação no âmbito de um colóquio em Ottawa, seguida de outras em congressos e conferências no Brasil, oportunidades durante as quais pretendíamos esclarecer vários conceitos e propor uma perspectiva a partir das constatações preliminares feitas in loco, com o intuito de integrar os dados primários e secundários levantados graças à observação, às entrevistas e aos diferentes documentos (oficiais, de associações, jornais e relatórios) relacionados ao nosso objeto de estudo, durante e após essas pesquisas de campo.

1. Conforme os últimos dados e o mais recente censo da população (2014), Angola tem 24.383.301 habitantes e a cidade de Luanda ultrapassou os cinco milhões de habitantes.

\section{I}

A capital de Angola, Luanda, passou de cerca de 500 mil moradores - no momento da Independência, em 1975 - a cinco milhões em 2011 (estimativas não oficiais), ou seja, a população decuplicou em 26 anos ${ }^{1}$. Apesar de seu lugar de destaque na sociedade angolana, Luanda corresponde à imagem do país e cerca de $50 \%$ do tecido urbano da cidade é formado por musseques (favelas no Brasil, "bidonvilles" na França ou "shanty towns" nos Estados-Unidos). De acordo com a Organização das Nações Unidas (ONU), citada pela agência oficial das notícias de Angola (Angop), essa tendência não cessa de aumentar:

Se medidas eficazes não forem tomadas para conter seu crescimento acelerado e desordenado, a cidade de Luanda poderá che- 
gar a 10 milhões de habitantes em 2020 , com $75 \%$ da população morando em musseques, conforme o relatório das Nações Unidas (Angop, 2006).

Consoante a definição substancialista e positivista que caracteriza as instituições estatais e internacionais, os relatórios anuais produzidos por pesquisadores da Universidade Católica de Angola afirmam que $65 \%$ da população angolana vivia com US\$ 2,00 ou menos por dia em 2008, número idêntico ao de 2002. Hoje, ninguém duvida que parte importante da população do segundo maior produtor de petróleo da África negra e de uma das cidades mais caras do mundo, vive, desde 2010, em condições de extrema pobreza, exibindo taxas de mortalidade infantil entre as mais elevadas do mundo, um déficit crônico de água potável, taxas de analfabetismo também muito elevadas, assim como epidemias periódicas de doenças infecciosas e contagiosas como a malária e a cólera. Com certeza, isso constitui uma violência revoltante e absurda para uma das populações mais fragilizadas de Angola, bem como uma violação de seus direitos mais fundamentais.

A fraqueza de infraestrutura sanitária, habitacional e educativa; de saúde e de higiene pública, de distribuição de água potável, de eletricidade e de vários outros serviços essenciais nos bairros da capital classificados como pobres, continua crítica porque essa infraestrutura é terrivelmente falha e problemática. Vários críticos revelam um desprezo imoral em relação à situação e às condições sociais dessas populações, apesar dos esforços concretos, que devem ser reconhecidos - feitos pelo governo angolano nesses últimos anos, com o intuito de resolver a situação. Esses esforços são mais do que necessários, mesmo que insuficientes e, frequentemente, mal concebidos e ineficientes em relação ao consumo de luxo dos que governam e amontoam riquezas.

A economia da cidade tem duas faces: aquela das elites nacionais e estrangeiras, muitas vezes decorrente da criação improdutiva de uma renda vinda da extração e da exploração de matérias-primas como o petróleo e os diamantes, da importação e do comércio, da especulação imobiliária e da construção civil. Aqui devemos relembrar que o desenvolvimento imobiliário se destaca de várias formas com a reconstrução da infraestrutura de base que foi destruída durante a guerra civil (estradas, ferrovias, portos, aeroportos e barragens). Ele se destaca também com a reconstrução das ruas e dos prédios urbanos, sobretudo aqueles que pertencem ao poder do Estado e ao poder econômico e que foram destruídos no momento da guerra civil ou, da mesma forma, com a construção de novos edifícios e mansões de luxo que satisfazem o gosto e permitem o esbanjamento dos novos-ricos.

O desenvolvimento imobiliário fundamenta-se na especulação fundiária do espaço urbano, a disputa pela terra e pela água, sem a intervenção do Estado, salvo quando se 
trata deste autopreservar-se ou proteger sua clientela. Mais ainda: o desenvolvimento em curso está quase exclusivamente voltado à acumulação rápida e à apropriação de riquezas naturalmente ilegítimas e, na maioria das vezes, juridicamente ilegais e anticonstitucionais. Por sua vez, o Estado angolano - instrumentalizado pelo direito, pela Justiça, pela polícia e pelos tribunais - qualifica os cidadãos, suas principais vítimas, como pobres, perigosos, delinquentes e criminosos. O direito de resistir e de se opor à norma e à força constrangedora do Estado, fundamento da cidadania democrática, no melhor dos casos é utilizado como obstáculo social e político e, no pior deles, como contestação. Assim, os cidadãos que resistem e que não aceitam ser expulsos de suas moradias são classificados como pobres, perseguidos e identificados como baderneiros e desordeiros, nunca como cidadãos com direitos e liberdades. O Estado expulsa, surra, aprisiona e, às vezes, mata em nome do seu direito e da sua justiça!

Este desenvolvimento do setor imobiliário fica evidenciado sobretudo nos shoppings centers e nos hotéis de luxo, nos condomínios fechados e nos arranha céus de grande requinte (residenciais e comerciais), no tráfico de influência, de divisas, de bens e serviços que satisfazem as necessidades incomensuráveis e improdutivas de uma elite dirigente angolana, minoritária em termos demográficos, porém muito bem colocada em termos de tirar proveito da situação justamente por sua proximidade com o Estado e pelo acesso às redes de influência política instaladas, o que lhes permite gerar importante renda a partir de transações realizadas com uma clientela estrangeira.

Aqui, não se trata apenas de um caso especificamente angolano, visto que, como bem observa o historiador senegalês Ibrahima Thioub:

Em qualquer cidade africana, fico impressionado pela coexistência entre um grande número de camionetes $4 \times 4$ de luxo e o uso de meios de transportes que datam do neolítico - a cabeça das mulheres. Isso significa que as elites, exercem a mais extrema violência sobre as populações, apossando-se dos recursos do país, exportando-os e gastando a receita gerada para a compra no exterior de bens de luxo inteiramente inúteis, de um ponto de vista social, mas simbolicamente com grande capacidade de violência. Elas arruínam os países sugando a força de trabalho dos corpos subalternos reduzidos à absoluta miséria (Thioub, 2010, grifos nossos).

Essa política urbana do Estado angolano depara-se, contudo, com o protesto da grande maioria de cidadãos deserdados e deslocados pela guerra, vítimas das disputas políticas e da violência das diferentes facções da elite, que continuam, desde a Independência, brigando pelo controle do Estado.

De fato, essa população que chegou à capital ao longo desses 39 últimos anos, há muito tempo ocupa uma área do espaço urbano importante em Luanda. Esse terri- 
tório é cobiçado pelos empreendedores nacionais e estrangeiros. Então, ela poderia reivindicar seu direito ao usucapião contra o direito do Estado nos tribunais de primeira instância, podendo ainda recorrer à Corte Constitucional e à Suprema Corte. Trata-se de um direito pacífico e público de aquisição da propriedade pelo seu uso, nesse caso das terras ocupadas pelos moradores de musseques, conforme os termos previstos nas leis sobre a determinação do tempo de ocupação e da prova de seu uso, isso independentemente dos títulos de propriedade e de todo e qualquer constrangimento violento.

Obviamente, o Estado angolano pode argumentar sobre a importância desses espaços $^{2}$ - áreas ocupadas pelos pobres há muito tempo - para implementação de seus programas por motivação de "utilidade pública", ou seja, em nome do bem comum. Para isso, ele deveria provar que o objeto de sua demanda está relacionado com o bem-estar de todos os angolanos, e não com uma apropriação voltada para o ganho fácil e indevido, mas também proceder a expropriações negociadas com cautela e inteligência, indenizando os cidadãos pobres, pagando o valor real das terras que ocupam, ou seja, conforme os preços do mercado imobiliário dos especuladores (Estado e empresas). Esse preço está muito além da oferta de habitações sociais, visto que tem a ver com prédios de apartamentos e mansões de luxo, que esses pobres nunca poderão vislumbrar e ou pagar. O discurso oficial apresenta essas habitações sociais como os futuros alojamentos de uma classe média "emergente" que não pode ser confundida com as populações que vivem nos musseques.

Além de ser negligenciada pelas políticas de Estado e a elite dos predadores (Pepetela, 2005; Thioub, 2010), a grande maioria dos cidadãos pobres é frequentemente ignorada ou desprezada (Honneth, 2000; 2006) tanto pelos discursos falsamente éticos como pelas práticas injustas das primeiras (as políticas de Estado) e da segunda (a elite dos predadores), embora esteja ocupando e morando nas áreas centrais de Luanda há anos. Como o poder do Estado não impediu essa ocupação das classes desfavorecidas durante décadas, isso deveria significar que ele reconhece de fato e de direito a prática do usucapião. Assim, esses cidadãos construíram um modo de vida e uma identidade, implementando redes de sobrevivência, de ajuda e de solidariedade, para conquistar bens e serviços essenciais, dividi-los e compartilhá-los ou até mesmo, pelo menos para alguns deles, imaginar factível o ingresso nessa elite predadora. Em suma, em resposta à atitude e à reação dos grupos que dominam a sociedade angolana, as classes desfavorecidas se organizaram econômica e socialmente, muitas vezes sem o apoio do Estado ou da elite, para afirmar sua existência e reivindicar seu direito à cidadania:

Para sobreviver e assegurar a reprodução social, as famílias que vivem nos centros urbanos de Angola desenvolveram estratégias
2. O Estado angolano reivindica a propriedade da terra como direito líquido e certo. Esta lhe pertence naturalmente, da mesma forma que o monopólio legítimo da violência. 
3. Ver o conceito de "economia suja" de Vincenzo Ruggiero (1997).

4. Manteve- se, em português, a palavra reivindicatória, mais utilizada; entretanto, o autor fala em vindicatória e faz a seguinte nota: Aqui, fazemos uma distinção entre vindicatórias (reclamações e exigências que muitas vezes fazem referência à negociação e à restituição) e vindicativas (que tratam de atitudes retributivas e de vingança). que Ihes permitem responder às exigências da vida cotidiana. Os princípios fundamentais dessas estratégias visam concentrar e compartilhar os recursos entre os membros das famílias e suas redes de solidariedade e, de forma concomitante, multiplicar as fontes e os métodos necessários à criação e/ou à arrecadação desses recursos. Os cidadãos angolanos urbanizados comprovaram que seus esforços produzem resultados além da simples subsistência (Rodrigues, 2007).

No caso do Estado e da elite dominante, assim como no caso das populações pobres - em níveis certamente diferentes, em razão da natureza de cada um e das respectivas realidades -, as atividades paralelas ou ilegais constituem boa parte das ocupações implementadas no intuito de satisfazer às necessidades de cada categoria. Assim, os comportamentos legítimos e ilegítimos, lícitos e ilícitos, legais e ilegais dos diferentes atores estão interligados, criam e definem articulações originais e complexas entre as diferentes esferas da estrutura social angolana ${ }^{3}$.

Isso leva a observar diferentes ordens jurídicas que operam e que são evocadas para justificar as ações e os comportamentos de ambas as partes, mas também as demandas e as exigências reivindicatórias (vindicatórias ${ }^{4}$ ) dos atores, o direito e a liberdade de existir e, ao mesmo tempo, o reconhecimento de seu sofrimento, junto à exigência de reparação dentro e fora do campo do direito do Estado, ou seja, com referência ao direito do Estado, certamente, mas também ao direito costumeiro, ao direito dos nativos e ao direito popular ou espontâneo (dos Santos, 2009).

Todavia, isso levanta um problema maior: qual o lugar do direito positivo herdado do colonialismo português e qual o papel da justiça do Estado angolano quanto aos inúmeros comportamentos contrários ao que prescrevem, sem atingir, o direito e a justiça do Estado? Aqui, podemos apontar para o debate entre monolitismo e pluralismo jurídico, a relação entre as culturas jurídicas herdadas do colonialismo europeu, sua recepção local, e as nativas, assim como suas articulações dentro do respeito a uma democracia reflexiva baseada na noção de espaço público e os direitos cidadãos.

\section{II}

Consequentemente, no primeiro caso - do Estado e da elite -, as alianças são firmadas com empresas multinacionais e os Estados do Norte, embora novos atores estejam aparecendo, como os Estados e as empresas da República Popular da China, da Índia e, mais particularmente, do Brasil. No segundo caso - das populações consideradas pobres -, os especuladores nacionais que outrora controlavam as organizações paralelas tornaram-se "globalizados". Eles firmaram alianças com 
especuladores asiáticos (chineses e coreanos), mas também com africanos vindos de todos os lugares do continente, ou já foram mesmo até suplantados por estes e se tornaram sócios minoritários. Há alguns anos, assistimos à expulsão manu militari dos congoleses que entraram ilegalmente em Angola e que, em poucos anos, conseguiram dominar boa parte do comércio paralelo do país. Aliás, essas várias expulsões produziram um "certo mal-estar diplomático" com a República do Congo, mais particularmente quando as Nações Unidas anunciaram que, entre as pessoas expulsas, havia mais de 600 mulheres, dentre as quais várias tinham sido violentadas na fronteira entre os dois países (Gettleman, 2010).

Nos oito últimos anos e, sobretudo, com o fim da guerra civil, ocorre um enfrentamento violento entre diferentes facções que disputam a distribuição e posse da terra e da água, com consequências importantes no que diz respeito às moradias, ao alojamento e à saúde dos cidadãos angolanos que vivem nos musseques. No entanto, para que o enriquecimento improdutivo da elite minoritária continue, o verdadeiro desafio consiste em manter e em reproduzir as condições de pobreza, negando os direitos e as liberdades decorrentes da cidadania. Assim, pode-se questionar:

\begin{abstract}
O que diferencia a situação atual da escravidão? No passado, as companhias europeias traziam para África bens tão inúteis como devastadores, a exemplo das miçangas, do álcool e das armas. Elas os entregavam às elites que organizavam a caça aos escravos. Já, a pilhagem permitia a essas elites o acesso aos bens de consumo importados. Hoje, o sistema aperfeiçoou-se, visto que os escravos se entregam espontaneamente: são os imigrantes... Se você colocar um barco em qualquer um dos portos africanos e anunciar que está procurando escravos para a Europa, o barco ficará imediatamente lotado (Thioub, 2010).
\end{abstract}

O direito e a justiça do Estado, assim como a violência da força que os acompanha, aparecem como suporte desse enriquecimento e da formação do Estado angolano (dos Santos, 2007; Tilly, 1985). Ora, o que nos parece interessante e importante não é uma definição substancialista e positivista da pobreza que categoriza, classifica e organiza as pessoas para melhor criar a descrição de suas vidas como pobres, e, assim, contá-las e listá-las nas estatísticas e nos números de políticas econômicas e sociais - "os pobres" -, e isto é o que, muitas vezes, fazem os economistas, os estatísticos, os sociólogos e outros cientistas sociais.

\title{
III
}

Pretendemos olhar com outros olhos os pobres de Luanda, entender melhor sua situação como parte "da relação de assistência entre eles e a sociedade em que vivem" (Serge Paugam \& Franz Schulheis, 1998/2002: 14). Os pobres dos musseques 
5. Preferimos o termo "marginalização" dessas populações ao termo "exclusão", tal como o faz Robert Castel $(1994 ; 1995)$. só são pobres quando o Estado angolano e suas instituições aprisionam-nos nessa categoria preestabelecida e criam a condição que a acompanha - a pobreza - marginalizando seus componentes ${ }^{5}$, excluindo-os da possibilidade de participação na solução dos problemas da sociedade angolana como um todo. O Estado procura privá-los de sua condição de cidadãos, uma vez que não se submetem ao direito e à força do Estado, seja como pessoa, seja como grupo social. No melhor dos casos, eles são "assistidos sociais", uma minoria social que depende do Estado e de suas políticas. Essa submissão (nacionalidade) está longe de reconhecer sua condição de pertencimento à sociedade e à liberdade (cidadania), aquela que corresponde a uma estrutura mental e a uma identidade que Ihe é própria.

A política internacional de luta contra a pobreza segue os mesmos padrões. Reproduz a condição de pobreza em escala planetária, reforçando uma categoria jurídica e mental truncada - o pobre -, a qual impõe uma forma de ver e de pensar o mundo, de estruturá-lo e organizá-lo. Os pobres não são o resultado das relações que se firmam entre eles e que os unem, dando-Ihes uma "consciência coletiva" baseada em uma solidariedade infalível. O que os torna mais próximos uns dos outros é "a atitude coletiva que a sociedade, no seu conjunto, adota em relação a eles" (Paugam \& Schultheis, 1998/2002: 15). Os pobres - a exemplo dos criminosos - não estão à margem ou fora das nossas sociedades; eles estão nelas e, há muito tempo, reivindicam isso em relação às políticas de Estado e da ONU que os enxergam como excluídos, quando, de fato, eles são claramente marginalizados.

Entretanto, as elites e o Estado insistem em associá-los à desordem, "grupos de indivíduos que causam desordem, pessoas [...] inúteis que não conseguem ter um comportamento de consumidores" (Ruggiero, 2010: 164), são pessoas indolentes, incapazes de se integrarem ao mercado, visto que têm uma cultura do uso e não da troca. Assim, os pobres constituem "uma ameaça violenta" para a ordem do mercado, consequentemente são objeto de antipatia e medo, pois a desordem assim percebida é improdutiva. Não sobra nada além da rua para que os cidadãos pobres possam manifestar a sua existência e exigir os seus direitos. Mas, para os poderosos, se a rua não é mais seu "lugar de consumo e de festejo", é necessário acabar com sua força política enquanto força de "desordem", ou seja, controlá-la, reprimi-la ou proibi-la, promovendo o vazio (Ruggiero, 2010: 167-168). Eis a essência tanto da violência como do uso da força, sob pretexto da ordem e da paz. Paz? Que paz? Para quem essa paz?

É em nome do desenvolvimento nacional que o Estado justifica a necessidade de mercado, não da produção, mas do consumo e da distribuição, assim como a aliança firmada entre as elites angolanas, investidores dos quatro cantos e as grandes empresas estrangeiras. Entretanto, o mercado de consumo em questão permanece 
fora de alcance da maioria dos moradores dos musseques, e a produção nacional é insuficiente. Este mesmo Estado argumenta que seu direito é hegemônico e que tem o direito de usá-lo a seu bel-prazer. Pode ainda ditar as leis e fazer justiça segundo o seu próprio arbítrio e em proveito de seus aliados, sem respeitar ou reconhecer aqueles que chama de seus sujeitos. Defrontamo-nos, de fato, com uma situação em que as populações dos musseques de Luanda encontram-se sitiadas em condição de extrema pobreza, porque consideradas culpadas de indolência e constrangidas a interagir justamente com quem assim as estigmatizou.

Há muito tempo que esta barafunda,

continuum de mercados irregulares e ilegais na cidade e suas ruas... faz referência a uma variedade de indivíduos em interação com um mercado no qual as mercadorias e os serviços são comprados e vendidos sem preocupação quanto à sua legalidade ou ilegalidade...

e as barreiras, que delimitam o espaço social definido física, geográfica e simbolicamente, demarcam e distinguem os bairros pobres daqueles da sociedade da opulência e permitem realizar uma cartografia dos diferentes espaços da cidade. Por um lado, essa separação confina os valores morais e a economia de cada um dos espaços, e, por outro, assegura a reprodução de ambos (Ruggiero, 1996: 324-326). Então, a fronteira entre os dois é imaginária ou fictícia, visto que existe um movimento de troca de mercadorias e de serviços legais e ilegais entre os dois. É o que Vincenzo Ruggiero denomia a economia suja (1996; 1997).

Ao desencadear uma especulação imobiliária fora dos limites, o Estado angolano elege as populações que ele próprio estigmatiza como pobres como principal alvo, procura desalojá-las a qualquer custo, recorrendo, se necessário, à força para avançar as barricadas delimitadoras. Desconsidera o fato de os pobres de Luanda ocuparem esses bairros há muitos anos - tendo adquirido, como já adiantamos, o direito de usucapião estabelecido para as ocupações efetuadas durante um determinado período sem que a propriedade seja contestada - e reivindica ser o único e onipotente proprietário, cobiçando os bairros dos musseques para a realização de seu desenvolvimento urbano verticalizado de luxo, a construção de grandes arranha-céus de salas comerciais, shopping centers nos moldes do Ocidente, hotéis de luxo, grandes estádios, mansões, condomínios e resorts fechados, a exemplo das "gated communities" originárias dos Estados Unidos, que se multiplicaram no Brasil, nos países do Golfo Pérsico e em outros lugares do mundo, e que não conseguiram encontrar meios de resolver democraticamente os problemas, as agitações e os conflitos enfrentados pela população. 


\section{IV}

Ao invés de situar-se no âmbido de um espaço público (Habermas, 1993; Joseph, 1998)

...concebido como espaço de ação, domínio historicamente constituído da controvérsia democrática e ponto de partida de uma ética processual do agir comunicacional, cujo objeto é a elaboração de um acordo baseado sobre o uso da razão de forma livre e pública (do Santos, 2009: 119),

e de elucidar democraticamente a controvérsia que

seria um caso de conflito entre dois partidos (pelo menos) que não poderia ser solucionado de forma equitativa, na ausência de regras aplicáveis para julgar as duas argumentações (Lyotard, 1983),

o Estado cria um litígio, do qual ele espera que o veredito do mesmo, the seja seguramente favorável, na medida em que não existe "uma regra para o julgamento aplicável às duas argumentações". Isso quer simplesmente dizer que as partes de um conflito não podem ser consideradas como iguais. A balança sempre vai pesar para o lado daquele que faz e dita o direito, sobretudo quando tem o monopólio da força, que ele pode, se necessário, recorrer. Depois da resistência e da contestação dessas populações, do não reconhecimento moral de sua cidadania, de fato e de direito, e em decorrência dos resultados improdutivos da política repressiva e violenta do Estado que as definiu como classes perigosas, que esse mesmo Estado decidiu-se pela assistência como forma de regulação do litígio, ou seja, pela reconstrução da categoria dos pobres. Assim, é preciso criar, conforme as conjunturas sociais, econômicas e políticas, um laço específico entre essas situações ou problemas sociais e a totalidade social. Para o Estado angolano, trata-se de implementar os meios pelos quais poderá alcançar seus objetivos, mas, para as populações dos musseques, trata-se do reconhecimento de seus direitos e da construção de uma identidade e um vínculo social que lhes permita tornar mais visível, mais constante e forte seu sentimento de estar socialmente incluído, de encontrar seu devido lugar na sociedade angolana, em outros termos, sua cidadania.

É o caso, por exemplo, da inclusão de alguns projetos de construção de moradias sociais para as populações dos musseques, de novos postos de saúde, da renovação de feiras e mercados nos bairros populares como Sambizanga, Prenda, Viana, Benfica, Cazenga, Kilamba Kiaxi, ainda que isso não responda, nem de longe, às reais necessidades. Isso não resolve a situação, pois a recolocação dessas populações as afasta dos locais de sua vida cotidiana e de seu trabalho, levando a rupturas terríveis 
em sua vida social e familiar. Ademais, as populações em questão não participam das decisões que as afetam diretamente, pois não existe espaço público! Diante do reconhecimento legal do Estado que não passa de ficção e do não reconhecimento social dos direitos e das liberdades dessas populações pobres, segue-se também o "insulto moral" (Cardoso de Oliveira, 2002) de não escutá-las, ignorando suas demandas para além do direito formal e institucional do Estado angolano, ou seja, da mera aplicação do direito constitucional angolano ou dos instrumentos jurídicos internacionais como a Carta dos Direitos e das Liberdades Africanas ou a Carta Universal dos Direitos do Homem das Nações Unidas. É preciso recorrer ao pluralismo jurídico para encontrar algum reconhecimento ou transcender o insulto moral, fonte de violenta opressão e de consideráveis desigualdades.

Frequentemente, como já afirmamos, essa situação significa um deslocamento dessas populações para espaços distantes dos seus lugares de residência e trabalho de origem (dezenas de quilômetros), quebrando os laços construídos ao longo dos anos, com uma burocracia administrativa complicada, o que dificulta os deslocamentos e a adesão dessas populações a esses projetos difíceis, além de levar ao crescimento dos movimentos de resistência e de recusa. As políticas de Estado de financiamento de moradias também fracassam e estão sobretudo direcionadas ao desenvolvimento e fortalecimento de uma classe média vinculada ao setor administrativo, aos serviços, à circulação dos bens e do capital, portanto improdutiva, e não à solução dos problemas que assolam as populações dos musseques, apesar do planejamento e da implementação de projetos de moradias populares. Os atores dessas políticas são sempre os mesmos: o Estado, as elites angolanas e, sobretudo, três grandes empresas de construção civil, duas portuguesas - a Teixeira Duarte e a Soares da Costa ${ }^{6}$ - e uma brasileira - a Norberto Odebrecht. Hoje, é preciso também acrescentar, como já foi afirmado, empresas chinesas e indianas.

\section{V}

Enquanto vários projetos de infraestrutura encontram uma justificativa política, econômica e até social, como no caso do novo Aeroporto Internacional de Luanda, ou dos espaços verdes e equipamentos de lazer, a reconstrução de estradas, pontes, barragens e ferrovias, obras que, na maioria das vezes, são conduzidas por empresas chinesas, outros têm mais a ver com a megalomania do Estado e de seus clientes, com a possibilidade de negócios lucrativos de curto prazo, influenciados pela loucura de grandeza da nova burguesia de negócios presente no aparelho de Estado. Essa política do estatal é definida a partir de termos pomposos e "técnicos", como a "requalificação urbana" e a redefinição das "novas centralidades". A construção da "cidade satélite" de Kilamba7 por empresas chinesas, a 30km de Luanda, é um exemplo claro do estado de espírito das elites angolanas. Concebida a partir

\footnotetext{
6. Empresa hoje controlada por um empreendedor angolano ligado ao Estado.

7. Ver o artigo sobre Kilamba do primeiro ministro da saúde pós-Independência de Angola, Mario Afonso, assim como muitos outros escritos sobre essa "cidade fantasma", facilmente encontrados na internet.
} 
da ideia de que era preciso diminuir a sobrecarga pesando sobre a capital, e alojar cerca de 500 mil habitantes - a nova classe média -, a "cidade satélite" apresenta, ainda hoje, um aspecto "bastante desolador", um ar de cidade-fantasma. Ela custou mais de U\$ 3,5 bilhões e, embora o preço dos apartamentos e das casas tenha diminuído de forma constante, por enquanto, não atraiu compradores. Em realidade, essa "nova classe média" ainda não está em condições de pagar o preço demandado para a aquisição desses bens imóveis, nem de enfrentar os especuladores do mercado imobiliário e a burocracia do Estado, muito menos os bancos que fazem empréstimos com taxas de juros exorbitantes.

Foram construídos novos estádios de futebol, imensos, um grandioso complexo universitário em Luanda, com tecnologias de ponta, enquanto as universidades têm dificuldades de funcionamento, um parlamento e um moderníssimo parque contíguo aos ministérios! Então, não se trata apenas de uma questão financeira ou de crescimento econômico, mas, sobretudo, trata-se de uma questão moral e de desenvolvimento, ou seja, de constituição de uma lógica igualitária ligada aos direitos da cidadania, ao reconhecimento das diferenças que envolvem a identidade de todos os angolanos, assim como das diferentes formas de participação e de contribuição à riqueza nacional. De fato, esses últimos anos, o frenesi imobiliário que se apoderou do Estado angolano parece indicar uma vontade de rápida recuperação econômica, após 30 anos de guerra civil. No entanto, consoante Emmanuel Carneiro, ex-ministro do planejamento e da economia,

... a construção de infraestruturas tem um efeito bastante limitado sobre o crescimento dos setores nacionais produtivos. O desenvolvimento é algo de muito mais complexo do que a execução das grandes obras públicas. Trata-se de um processo multidimensional de transformação endógena. Consequentemente, a gente se depara como uma modernidade sem desenvolvimento, uma pseudomodernidade, totalmente mimética.

... Nós corremos o risco de construir estradas ou prédios luxuosos etc. para servir uma economia de "casino" ou, simplesmente, a reciclagem de uma renda externa... Hoje, existe de forma evidente um enfraquecimento das instituições formais do Estado. A participação de atores da iniciativa privada, a privatização de fato das instituições, são formas atuais de governança... A lógica da renda transforma tudo em mercadoria, até o desenvolvimento é comprado. Tudo se compra, tudo se vende (Carneiro: 22-23).

Um exemplo: o Belas Shopping, construído por arquitetos brasileiros, na zona sul de Luanda, onde também foram construídos condomínios fechados de luxo. O centro comercial, como o conhecemos hoje, nas sociedades de produção e de consumo de massa, não corresponde de forma alguma à sociedade angolana, cujas atividades de 
produção são fracas e o nível geral de consumo baixo, exceto para as elites. O shopping center não preenche as condições de um espaço público, pois é fundamentalmente um espaço de comércio, de trabalho e, talvez, de lazer mercantil, com um sistema prático, que oferece comodidades na medida em que há uma diversidade de produtos, segurança, e um ambiente propício ao aumento e à manutenção dos níveis de consumo. O preço disso tudo é um modo de vida e de consumo quase sem sentido crítico e consciência social, o que leva a uma perda de liberdade cidadã. No âmbito de uma sociedade como a angolana, o shopping center parece mais com um espaço de exclusão e marginalidade social, na medida em que muda e regula as culturas e as identidades, vende e promove imagens inaccessíveis para a maior parte dos moradores de Luanda, aqueles mesmos que, para além da Constituição angolana, gostariam de ser reconhecidos como cidadãos de direito. Por outro lado, o shopping se opõe ao espaço público porque se apresenta como se fosse um desses espaços, sem a imagem da miséria e da decadência social que caracteriza os musseques e seus modos de organização, que o Estado angolano, suas elites e os "estrangeiros" gostariam de ver desaparecer.

Todavia, levar adiante esse plano de construção imobiliária é, para o Estado angolano, tão só uma questão de espaço, sobretudo de espaço urbano. Isso constitui a chave para alcançar benefícios e rendas futuras gigantescas. O espaço urbano é essencial para que o Estado angolano mude a imagem de suas cidades, mas também em relação aos seus parceiros de negócios, às empresas e aos Estados estrangeiros, propalando uma melhor forma de vida para sua clientela nacional e estrangeira. Um espaço à imagem deste beautiful people e de seu bem-estar, pouco importando onde estejam, mesmo se isso significa ignorar as necessidades da grande maioria dos pobres de Angola! O problema é que esse espaço urbano foi ocupado pelas vítimas da guerra e de sua violência, pelos camponeses que deixaram o campo, enfim, por todos aqueles e aquelas que buscaram refúgio na cidade. Então, o Estado, que se declarou o único verdadeiro proprietário da terra, desrespeitando o direito de usucapião - exceto quando reconhece a propriedade privada de seus clientes -, empreendeu como desejou, isso muitas vezes de forma violenta, reivindicando seu "direito" líquido e certo sobre o espaço.

\section{VI}

Condomínios foram construídos para os patrões e empregados das companhias estrangeiras de petróleo, das empresas nacionais e multinacionais, assim como para os novos-ricos angolanos, sobretudo na parte sul e no centro da capital. Além da reforma do centro histórico e da região da Baía de Luanda, assim como da futura ampliação do porto de Luanda, esses projetos aumentaram a pressão sobre os musseques e seus moradores. Várias tentativas de expulsão forçada dos pobres da cida- 
de de Luanda terminaram em confrontos sangrentos entre, de um lado, o Estado, sua polícia e seu exército; de outro, os cidadãos e cidadãs pobres, os moradores dos musseques, ora reunidos em associações ou movimentos sociais, ora em movimentos espontâneos de resistência e oposição:

Em julho de 2001, após terem sido expulsos à força de suas casas em Boavista, bairro perto do porto de Luanda, capital de Angola, milhares de famílias moraram em tendas durante quase dois anos. Do final de 2001 até dezembro de 2002, mais de 1.000 casas de Soba Kapassa, bairro situado na zona Sul de Luanda, foram derrubadas, deixando os moradores sem teto. Em abril de 2003, mais de 470 casas foram destruídas em Benfica; algumas das famílias assim expulsas foram realojadas em um complexo imobiliário social do Estado, na Zona Norte de Luanda, a quase $40 \mathrm{~km}$ de suas casas de origem. Todas essas expulsões eram arbitrárias e foram levadas a cabo pela polícia com a força das armas. Na maioria dos casos, não havia alojamentos suficientes e adequados, como alternativa à destruição das casas dessas populações (Amnesty International, 2003: 1).

E ainda,

Entre 2001 e 2006, milhares de famílias foram expulsas à força de vários bairros da capital angolana. Essas expulsões violentas foram feitas sem notificação prévia ou consultas, sem respeitar as regras processuais que acompanham a aplicação das leis, e com um uso excessivo da violência. As expulsões à força deixaram milhares de pessoas sem moradia. Na maior parte dos casos, membros da Polícia Nacional ou das Forças Armadas de Angola (FAA) foram encarregados dessas expulsões, atiraram sem discriminação sobre os cidadãos expulsos, bateram e prenderam os que resistiram. Casas e propriedades foram destruídas e roubadas por aqueles que eram encarregados das expulsões. Em quase todos os incidentes gerados por essas expulsões forçadas, a polícia também prendeu militantes dos direitos humanos, sobretudo membros das organizações locais de defesa dos direitos à moradia, como SOS Habitação (Amnesty International, 2007: 2).

As expulsões pela força violam todo um conjunto de direitos dessas populações. Desrespeitam os direitos civis e os direitos humanos com respeito à condição da cidadania, em particular aqueles ligados às necessidades básicas, ao direito do usucapião e ao direito à moradia justa, parte integrante do direito a um modo de vida decente reconhecido pelo direito internacional, pelo direito africano e pela Constituição angolana. As expulsões submetem também contingentes populacionais ao arbítrio e às ilegalidades por parte dos agentes do Estado, pois elas são geralmente seguidas de violências e maus tratos, de uso abusivo da força que, às vezes, sacrifica 
vidas. O direito a um advogado é recusado às famílias, assim como o recurso aos tribunais ou a uma indenização após falsas acusações, danos materiais e morais. Entretanto, todos esses direitos e garantias individuais e coletivas são inscritos e protegidos em tratados internacionais que dizem respeito aos direitos da pessoa humana, e ratificados pelo Estado angolano, como, por exemplo, a Carta Universal dos Direitos do Homem das Nações Unidas, a Carta Africana dos Direitos dos Povos e do Homem. Em 9 de outubro de 1990, foram ratificados dois acordos internacionais sobre os direitos das mulheres e os direitos civis e políticos, a Carta Internacional dos Direitos da Criança foi assinada em 10 de janeiro de 1992, assim como outros instrumentos jurídicos internacionais e tratados sobre os direitos das pessoas humanas e regras processuais.

Em dado momento, no dia 13 de março de 2006, membros da Polícia Nacional e guardas de segurança de uma companhia privada - Visgo -, acompanhados de outros indivíduos vestidos à paisana, chegaram em Cambamba II com tratores e destruíram 200 casas. Os moradores, na maioria mulheres, crianças e idosos, ficaram em pé na frente de suas casas e não quiseram sair de lá. Quando o diretor de Nova Vida chegou de carro, vários residentes jogaram pedras, enquanto outros jogavam diversos objetos sobre os policiais e guardas de segurança, que fugiram. Mais tarde, naquela manhã, os policiais e os guardas de segurança voltaram ao local, acompanhados por cem policiais da Brigada de Intervenção Rápida fortemente armados. Segundo testemunhas, eles saíram dos seus carros atirando para o ar e em direção ao chão. Bateram nos moradores, até mesmo em uma mulher grávida, o que lhe causou uma hemorragia. Um garoto de cerca de quatro anos foi baleado e levado ao hospital. A polícia falou que a criança não tinha sido alvejada e que, de fato, ela havia se machucado caindo dos braços da sua mãe durante a confusão decorrente das expulsões forçadas.

Em Cambamba I, onde cerca de 130 casas foram destruídas, um segurança armado com um AK47, arma automática, atirou nos pés de um jovem que tentava fugir. O segurança e sete agentes de polícia cercaram-no e bateram nele com cassetetes, dando-Ihe pontapés. Várias mulheres foram presas, dentre as quais Domingas Manuela Batista, que estava grávida. Helena André, Maria Ganga, Luciana Inácia e Leonora Martins Miguel foram presas com seus jovens filhos. Aquelas que resistiam eram jogadas ao chão e pisoteadas, inclusive uma mulher que carregava um bebê nas costas. Um homem, Alvarito Francisco Medina, também foi socado e preso... (Amnesty International, 2007: 10-11).

No auge do enfrentamento, os representantes do Estado angolano - incluindo mesmo o governador da província de Luanda à época - frequentemente justificavam 
as expulsões forçadas afirmando que as casas eram escolhidas ao acaso e que, de toda forma, eram ilegais, visto que, do ponto de vista do Estado, eram construídas em áreas pertencentes ao Estado e que integravam projetos governamentais de desenvolvimento, abrangendo programas habitacionais, ou que essas terras ocupadas pelos pobres pertenciam a um particular. A destruição das casas dos pobres continuaria, pois era "necessária", já que essas casas eram construídas de forma desordenada, no desrespeito aos regulamentos do Estado. Esse último devia punir as pessoas que insistiam em violar as leis. Toda e qualquer pessoa que recebeu um título provisório de um lote para construir, mas que não o fez nos prazos fixados pelo Estado, tinha a sua autorização caçada e o título era reatribuído àqueles e àquelas que demostravam ter capacidade financeira para construir num prazo de seis meses. De acordo com as autoridades provinciais, era mais do que tempo de acabar com a anarquia que imperava nos musseques, com alojamentos construídos a partir de materiais de recuperação (lataria, zinco, terra, papelão, madeira, tijolo etc.) e instaurar a ordem recorrendo ao direito e à lei (cf. Amnesty International, 2007: 6).

O governo da Província de Benguela proibiu e reprimiu qualquer protesto coletivo nas ruas da cidade de Benguela que denunciasse essa atitude do Estado angolano, fossem os manifestantes cidadãos pobres dos musseques ou militantes das associações cívicas apoiando suas reivindicações e direitos. As explicações dadas para justificar essa proibição e repressão eram: isso provocaria desordem e afrontaria a "ordem pública"! De agora em diante, o que acontece em Luanda, a capital, estende-se às principais cidades do país.

\section{VII}

Os musseques, como lugares e espaços urbanos de vida dos pobres, caracterizam-se pela ausência de política de proteção, de melhoria e de defesa do patrimônio social e cultural de seus moradores e, obviamente, pela insuficiência de infraestrutura, de equipamentos e de rede de transportes coletivos. Isso se deve a uma densidade demográfica elevada, ao acúmulo de sujeira decorrente da inexistência de serviços de limpeza, da ausência de conservação combinada à existência de barreiras arquitetônicas à sobrecarga e à raridade de espaços vitais de trânsito e convivência, o que complica ou incompatibiliza a concretização da dimensão cívica, típica do espaço público (Ferraz, 2010).

Tanto no que diz respeito à miséria do dia a dia dos moradores dos musseques, quanto à questão da terra e da água, encontramos um denominador comum, aquele da luta pelos direitos da cidadania - direitos e liberdades individuais, garantias cívicas e direitos do homem. Nós revelamos duas estratégias que se referem tanto às narrativas que os atores constroem a partir de suas situações e condições, quanto 
às práticas que decorrem delas.

Em relação à política pública ${ }^{8}$, o Estado reprime mais do que negocia. A negociação - ou a busca de um compromisso democrático - poderia levar a crer que ele é apenas um ator entre outros no âmbito do espaço público e que abdicaria de sua posição hegemônica, pois deveria reconhecer o insulto moral que ele inflige aos pobres, assim como a necessidade de respeitar os direitos de cidadania. O Estado seria obrigado a debater publicamente com os demais atores e a reconhecer a existência de outras posições. Em resumo, ele deveria negociar as situações de forma totalmente transparente. Ora, o Estado angolano criminaliza o que ele definiu e designa como a pobreza e a miséria - duplo insulto.

As populações assim categorizadas recorrem a uma estratégia que inclui várias táticas. Elas organizam-se econômica e socialmente para afirmar seus direitos de cidadania, independentemente do Estado, construindo laços sociais e identitários com grupos sociais próximos, exercendo toda uma série de atividades ilegais, assim definidas pelo direito do Estado, na medida em que o Estado e a elite não Ihes permitem agir de outra forma. É o caso dos gatos elétricos, das gambiarras telefônicas e das redes clandestinas de água; da implementação, sem autorização, de postos de saúde etc., como meio de acesso aos serviços essenciais devidos a todos os cidadãos. Esses comportamentos são decorrentes ao simples fato de o Estado e as classes ricas ignorarem essas populações, não as consideram como suas iguais, como cidadãs de fato.

A esses exemplos de iniciativas, tomados entre outros tantos, devem ser acrescidas as categorias de atividades econômicas exercidas por essas populações pobres para assegurarem sua existência material, a sobrevivência. Elas foram descritas por Carlos M. Lopes (2004) numa comunicação apresentada por ocasião do Congresso Luso-Afro-Brasileiro das Ciências Sociais de Coimbra:

Os candongueiros são operadores não oficiais ou informais que praticam a candonga (dos Santos, 1990), ou seja, negócios ilegais com fins especulativos, no intuito de realizarem benefícios, como os táxis de lotação, o transporte de passageiros e de mercadorias entre as residências, o trabalho e os mercados, com a ajuda de motoristas, controladores, recrutadores e flanelinhas; os/as kinguilas, "aquele/aquela que espera", geralmente mulheres, que operam o comércio ilegal de divisas, visto que somente o Banco Central, os bancos comerciais e as agências privadas têm essa prerrogativa concedida pelo Estado.

Os doleiros são geralmente homens e trabalham como banqueiros informais, pois emprestam dinheiro. Porém, às vezes, são também agentes de segurança, protetores das kinguilas, visto que, frequentemente, elas são vítimas de assaltos ou de
8. Nós diferenciamos a política pública da política do Estado. A primeira faz referência à existência de um espaço público no âmbito do qual todos aqueles e aquelas que têm interesses quanto a essa política dela participam democraticamente, desenvolvendo uma ação pública legal e assumindo em conjunto a responsabilidade dos resultados; a segunda faz referência às vontades políticas dos Estados, que impõem suas decisões, mobilizando agentes escolhidos capazes de obter os resultados definidos pelo próprio Estado. 
roubos porque transportam valores importantes em divisas estrangeiras, até mesmo falsa moeda. Os roboteiros são preferencialmente jovens de sexo masculino que realizam trabalhos físicos e manuais de consertos ou de transporte (em carrinhos de madeira) de mercadorias até os mercados, para os comerciantes. A maioria desses jovens é composta por meninos de rua, órfãos e refugiados de guerra. Por outro lado, eles são conhecidos como consumidores de drogas, sobretudo de produtos químicos (gasolina) e, de forma ocasional, de maconha (haxixe).

Os/as zungueiros/as, geralmente jovens mulheres, são vendedores/as ambulantes de mercadorias (peixes, frutas, roupas etc.) que percorrem a cidade e seus bairros.

Essas populações organizam-se para defender seus direitos, constroem suas próprias instituições ou criam movimentos sociais, associações de bairro, formas de proteção civil, postos de saúde. Elas procuram e firmam alianças com organizações e instituições da sociedade civil, tais como igrejas, ONGs. Todavia, de um ponto de vista individual, elas também corrompem o Estado e seus agentes, se necessário for, recorrendo a ferramentas próprias do regime político e econômico, a exemplo da pequena corrupção cotidiana nas ruas. Os principais beneficiários dessa tática são, com certeza, os policiais de rua, os servidores públicos de menor cargo, sobretudo da alfândega, e aqueles que usam de "incentivos e sanções" com os pobres.

\section{A título de conclusão}

Frente à imoralidade, à violência e ao direito do Estado angolano, os pobres de Luanda constroem eles mesmos sua cidadania. Todos nós fazemos julgamentos de valor sobre o bem e o mal, o justo e o injusto. Se aceitarmos o fato de que a nossa necessidade de reconhecimento está intimamente ligada ao que cada ser precisa para desabrochar no âmbito de uma comunidade de iguais, a qual reconhece, ao mesmo tempo, que somos todos diferentes, devemos entender que a cidadania não depende apenas do Estado, de suas elites dirigentes e dos proprietários, mas da forma e do conteúdo da organização social. Em outros termos, depende dos modos de construção dos laços sociais e das identidades, de nossas relações com o outro. Isso traz à tona a questão da distribuição da riqueza (justiça social), mas também do reconhecimento da diferença (identidade cultural) que coloca em evidência a questão da igualdade, à qual terá de ser acrescida a da representação (dimensão política).

Suponhamos ser possível eliminar todas as injustiças relacionadas à distribuição das riquezas e resolver todas as injustiças ligadas à recusa de reconhecimento. Haveria ainda injustiça, um obstáculo capaz de impedir que parte das pessoas fosse representada como os demais no âmbito da vida social? Certamente, caso você inte- 
grar um sistema político que nega de forma sistemática o acesso à representatividade política de vários grupos que, consequentemente, nunca conseguem ver suas ideias debatidas no Parlamento (Fraser, 2009: 32).

Tudo isso remete ao centro do debate o problema da cidadania e do Estado, problema que está no cerne da democracia reflexiva, que articula as esferas econômicas, culturais, jurídicas e políticas. Assim, a análise deverá situar-se no âmbito de práticas sociais concretas, muito mais do que exclusivamente normativas. A cidade de Luanda ainda parece reproduzir o modelo que a marcou durante o período colonial, como se ela fosse de fato duas cidades: a do asfalto e das belas mansões, dos novos arranha-céus dos ricos e dos poderosos, cidadãos com direitos; e aquela de chão batido, com modestas moradias, de barracos, sem acesso aos serviços fundamentais, ocupada pelos pobres, não cidadãos, justamente porque marginalizados, fora do circuito mercantilista dominante, e assim definidos e tratados pelo Estado. Como outrora, com a violência do Estado colonial em Angola da ditadura portuguesa, até 1975, o uso abusivo da violência pelo Estado angolano independente, para impor políticas de Estado, não conseguiu resolver os problemas da cidadania e da sociedade angolana. Mesmo quando se invoca a sacralidade do direito do Estado e do seu monopólio da legítima violência como meio de justificar o mito da supremacia e da hegemonia do Estado!

Infelizmente, Luanda é una e indivisível. Sem os musseques, a cidade não existe! O Estado angolano deve imperativamente começar a reconhecer que os musseques não estão fora da cidade e que é preciso reabilitá-los e renová-los urgentemente, escutando os pedidos de seus moradores pobres, ou seja, colocá-los no exercício permanente de sua cidadania, para criar espaços públicos capazes de instaurar uma democracia em movimento e tornar efetiva a aplicação dos direitos.

Na ausência de mudança de atitude por parte do Estado e das elites angolanas, as populações pobres não se contentarão de apenas manifestarem seu desacordo com as políticas do Estado, mas serão impelidas a construírem uma cidadania militante para além do espaço privilegiado do Estado, uma cidadania que Ihes permita buscar outros modos de criação e partilha das riquezas, de reconhecimento da sua identidade, mas também de participação política nas decisões que lhes dizem respeito. Diante da arrogância do "você sabe com quem está falando?" (Da Matta, 1997) que relembra sem cessar a hierarquia social, essas populações já estão, há gerações, marcadas por formas culturais próprias de recorrer ao jeitinho angolano, a exemplo dos brasileiros (Barbosa, 1992), e de produzir formas culturais híbridas, a cultura caluanda dos pobres, que lhes agrada mais do que os produtos culturais importados, sejam eles dos Estados Unidos ou do Brasil, visto que eles se adaptam mais apropriadamente às suas necessidades. 
Abstract: This paper analyses urban problems in Angola's capital based on two surveys from the end of 1908s: the first one about Angola's parallel economy, and more specifically about Luanda's parallel economy, and the second one about urbanization policies in the sub-Saharan African suburbs. It also reviews new research done between 2006 and 2010, focused on understanding the new reality of the region 20 years later, as well as on describing and analyzing the eventual changes and their causes, according to the narratives and practices of the social actors involved. The emphasis of the paper is on analyzing the development of real state generated by the reconstruction of the infrastructures destroyed during the civil war, highlighting repeated disputes between the Angolan State and the populations of citizens disinherited and displaced by war, i.e., the victims of political struggles and violence from different groups from the elite which have been fighting to control the State since independence.

Keywords: poverty, moral, urbanization, rights, social exclusion, violence, citizenship.

\section{Referências}

ALLIX, Grégoire. L'ONU s'alarme de la fracture sociale dans les villes. Le Monde, 24 Mar. 2010, p. 4.

AMNESTY INTERNATIONAL. Angola: mass forced evictions in Luanda - a call for a human-rights based housing policy. London: Al Index: AFR 12/007/03, Nov. 2003.

Angola, lives in ruins: forced evictions continue. London: Al Index: AFR 12/001/2007, 2007.

Above the law. Police accountability in Angola. London: Amnesty International, 2007.

ANGOP/ANGONOTÍCIAS. Mais de metade da população de Luanda poderá viver em musseques até 2020. 26 Jul. 2006. Disponível em : <http://www.angonoticias. com/Artigos/item/10131>. Acesso em: 26 Set. 2009.

BARBOSA, Lívia. O jeitinho brasileiro. A arte de ser mais igual que os outros. Rio de Janeiro: Campus, 1992.

BERNARD, Philippe. À Luanda, les taudis côtoient les immeubles des nouveaux riches du pétrole. Le Monde, 10 Out. 2008, p. 5.

CARDOSO, António. Baixa \& Musseques. Luanda: União dos Escritores Angolanos, 1985 [1961].

CARDOSO DE OLIVEIRA, Luís Roberto. Direito legal e insulto moral. Rio de Janeiro: Relume Dumará, 2002.

CARNEIRO, Emmanuel. Une économie de rente n'a jamais produit de développement. Entretien, Afrique Asie, Mar. 2009, p. 22-23. 
CASTEL, Robert. Les métamorphoses de la question sociale. Une chronique du salariat. Paris: Fayard, 1995.

La dynamique des processus de marginalisation: de la vulnérabilité à la désaffiliation. Cahiers de Recherche Sociologique, n. 22, 1994, p.11-27.

CENTRO DE ESTUdOS E INVESTIGAÇÃO CIENTÍfICA. Relatório Económico de Angola, Luanda, Universidade Católica de Angola, 2002, 2003, 2004, 2005, 2006, 2007, 2008 e 2009.

CHAUMONT, Jean-Michel; POURTOIS, Hervé (Dir.). Souffrance sociale et attentes de reconnaissance. Autour du travail d'Axel Honneth. Recherches sociologiques, $\mathrm{v}$. XXX, n. 2, 1999.

DALRYMPLE, Theodore. What is poverty? City Journal, Set. 1999. Disponível em: <http://www.city-journal.org/printable.php?id=137>. Acesso em: 2 Fev. 2010.

D’ALMEIDA, Mário Afonso. Ainda as centralidades...Novo Jornal, 22 Fev. 2013, p. 23.

DA MATTA, Roberto. Sabe com quem está falando? Um ensaio sobre distinção entre indivíduo e pessoa no Brasil. In: DA MATTA, Roberto. Carnavais, malandros e heróis. Rio de Janeiro: Rocco, 1997.

DAVIS, Mike. Planet of slums. New Left Review, n. 26, Mar.-Abr. 2004, p. 5-34. Disponível em: <http://newleftreview.org/?view=2740>. Acesso em: 17 Nov. 2009.

- Le pire des mondes possibles. De l'explosion urbaine au bidonville global. Paris: La Découverte, 2006-2007.

DOS SANTOS, Daniel. Contar uma história e fazendo história. Elementos para uma análise histórica da justiça em Angola. Revista Ciências Sociais, v. 15, n. 2, 2009.

- A formação do Estado em Angola na época da globalização. Antropolítica, N. 22, p. 95-125, 1ㅇs. sem. 2007, .

The second economy in Angola: esquema and Candonga. In: ŁOŚ, Maria (Ed.). The second economy in marxist States. London: The Macmillan Press, 1990.

_. Plus ça change, plus c'est pareil! Capitalisme périphérique, urbanisation et environnement. L'Afrique des années 1970-1980. 1989, mimeo.

—. Dossiê. Vaincre la pauvreté. Alternatives Économiques, n. 237, Jun. 2005, p. 46-60. 
FERRAZ, Susana. Compreender o espaço público para requalificar a cidade. Luanda, 2007. Disponível em: <seu2007.saau.iscte.pt/Actas/Actas_SEU2007_files/Susana_ Ferraz2.pdf>. Acesso em: 17 Jul. 2010.

FRASER, Nancy. Qu'est-ce que la justice sociale? Reconnaissance et redistribution. Paris: La Découverte, 2005.

2009

Les dilemmes de la justice. Sciences Humaines, n. 203, p. 31-33, Paris, Avr.

_. Abnormal Justice, 2010. Disponível em: <www.law.yale.edu/documents/ pdf/Intellectual_Life/Itw_fraser.pdf>. Acesso em: 05 Maio 2010.

GALBRAITH, John Kenneth. L'art d'ignorer les pauvres. Paris: Éditions les Liens qui Libèrent; Le Monde Diplomatique, 2011.

GANS, Herbert J. The positive functions of poverty. The American Journal of Sociology, v. 78, n.2, p. 275-289, 1972, .

- The war against the poor. New York: Basic Books, 1996.

GETTLEMAN, Jeffrey. Hundreds were raped on Congo-Angola border. The New York Times, 5 Nov. 2010. Disponível em: <http://www.nytimes.com/2010/11/06/world/ africa/06congo.html?_r=1\&nl=todaysheadlin>. Acesso em: 06 Nov. 2010.

GONÇALVES, António. Cenas que o museke conhece. La Habana: Instituto Cubano del Libro; Editorial José Martí, 2003.

HABERMAS, Jürgen. L'espace public. Archéologie de la publicité comme dimension constitutive de la société bourgeoise. Paris: Payot, 1993.

HARVEY, David. The right to the city. New Left Review, n.53, Set.-Out. 2008. Disponível em: <http://newleftreview.org/?view=2740>. Acesso em: 27 Set. 2009.

HONNETH, Axel. La lutte pour la reconnaissance. Paris: Éditions du Cerf, 2000.

—. La société du mépris. Paris: La Découverte, 2006.

HUMAN RIGHTS WATCH. "Eles partiram as casas". Desocupações forçadas e insegurança da posse da terra para os pobres da cidade de Luanda. HRW/SOS Habitat-Acção Solidária, v.19, n. 7(A). New York; Luanda, Maio 2007.

JOSEPH, Isaac. La ville sans qualités. La Tour d’Aigues: Éditions de L’Aube, 1998.

KHADRA, Yasmina. Les anges meurent de nos blessures, Paris: Julliard, 2013. 
LOPES, Carlos M. Candongueiros, kinguilas, roboteiros e zungueiros. Uma digressão pela economia informal de Luanda. Trabalho apresentado no VIII Congresso Luso-Afro-Brasileiro de Ciências Sociais. Coimbra, 16-18 Set. 2004. Disponível em: <http://www.ces.uc.pt/lab2004/pdfs/CarlosMLopes.pt>. Acesso em: 22 Ago. 2010.

LYOTARD, Jean-François. Le différend. Paris: Minuit, 1983.

MINISTÉRIO DO PLANEJAMENTO. Estratégia de combate à pobreza. Luanda: Direção de Estudos e Planeamento/República de Angola, 2003.

- Inquérito Integrado sobre o bem-estar da população. Relatório analítico - v. I. Luanda, Instituto Nacional de Estatística, 2011.

NASCIMENTO, Allan Victor Coelho. Demolições e desalojamentos forçados em Luanda (Angola) e perda de terras pelos agricultores familiares em Santarém (Brasil) vistos por uma ótica comparativa. XI Conlab, UFBA. Salvador, 2011. Disponível em: <www.xiconlab.eventos.dype.com.br/.../13067793>. Acesso em: 14 Mar. 2012.

NUSSBAUM, Martha. Une crise planétaire de l'éducation. Courrier International, n. 1025, 24-30 Jun. 2010, p. 32-35 et 37.

PAUGAM, Serge; DUVOUX, Nicolas. La régulation des pauvres. Paris: PUF, 2008.

PAUGAM, Serge; SCHULTHEIS, Franz. Introduction. In: SIMMEL, Georg. Les pauvres. Paris: PUF, 2002 [1998].

PEPETELA. Predadores. Lisboa: Publicações Dom Quixote, 2005.

PESTANA, Nelson. Angola: a pobreza, uma vergonha nacional, 2008. Disponível em: <http://pambazuka.org/pt/category/features/53120>. Acesso em: 22 Nov. 2012.

RAFAEL, Armando. Luanda despejou à força 20 a 30 mil pessoas. Diário de Notícias, Lisboa, 15 Maio 2007. Disponível em: <http://www.dn.pt/inicio/interior.aspx?content_id=657533>. Acesso em: 15 Maio 2007.

RAHNEMA, Majid. Quand la misère chasse la pauvreté. Paris: Fayard; Actes Sud, 2003.

ROCHA, João Manuel. "As crianças viam tudo e choravam", contam imigrantes violadas pela polícia angolana. Público, 22 Maio 2012, p. 25.

ROLNIK, Raquel (relatora especial para a ONU sobre habitação adequada), Entrevista por Cátia Silva. Revista 05, Série V, Jul.-Set. 2009, p. 4-6.

ROTHWELL, Phillip. Introduction. In: "Never Again" - Remembering Angola. Portuguese Literary \& Cultural Studies, 15/16, 2010, p. XIII-XXIII. 
RUGGIERO, Vincenzo. Social disorder and the criminalization of indolence. City, v. 14, n. 1-2, Fev.-Abr. 2010, p. 164-169.

Criminals and service providers: cross-national dirty economies. Crime, Law \& Social Change, v. 28, n. 1, 1997, p. 27-38.

RUGGIERO, Vincenzo; SOUTH, Nigel. La ville de la fin de l'ère moderne en tant que bazar: marchés de stupéfiants, entreprise illégale et les «barricades». Déviance et Société, v. 20, n. 4, 1996, p. 317-333.

RODRIGUES, Cristina Udelsmann. Survival and social reproduction strategies in angolan cities. Africa Today, v. 54, n. 1, 2007, p. 91-105.

RODRIGUES, Cristina Udelsmann; COSTA, Ana Bénard da (Dir.). Pobreza e paz nos PALOP. Rio de Janeiro: Sextante, 2009. Disponível em: <http://www.oplop.uff.br/sites/default/files/documentos/poverty-and-peace-in-the-portiguese-speaking-african-countries-2009.pdf>. Acesso em: 20 Out. 2011. 


\section{Errata}

No artigo "Encontro entre pobreza e moral em Luanda. Urbanização, direitos e violência", publicado no Volume 30 número 1 da Sociedade e Estado, páginas 99-122, na página 122, DOI: 10.1590/S0102-69922015000100007, acrescentar após a referência

RODRIGUES, Cristina Udelsmann; COSTA, Ana Bénard da (Dir.). Pobreza e paz nos PALOP. Rio de Janeiro: Sextante, 2009. Disponível em: <http://www.oplop.uff.br/sites/default/files/documentos/ poverty-and-peace-in-the-portiguese-speaking-african-countries-2009.pdf>. Acesso em: 20 Out. 2011.

as seguintes referências:

SILVA, Reginaldo. A economia angolana é uma das mais injustas de África. Economia \& Mercado, Ano 8, n. 34, p. 16-19, Nov.-Dez. 2006.

SIMMEL, Georg. Les pauvres. Paris: Presses Universitaires de France/Quadrige, 1998.

THIOUB, Ibrahima. L'Afrique et ses élites prédatrices. Entretien. Le Monde, 31 Maio 2010. <http:// lemonde.fr/idees/article/2010/05/31/I-afrique-et-ses-elites-predatrices-entretien>.

TILLY, Charles. War making and state making as organized crime. In: EVANS, Peter; RUESCHEMEYER, Dietrich; SKOCPOL Theda (Eds.). Bringing the State back in, p. 169-187. Cambridge: Cambridge University Press, 1985.

VALADIER, Paul. Morale en désordre, Paris: Éditions du Seuil, 2002.

VAN DER WINDEN, Bob (Ed.). A family of the musseque. London: World View Publishing; One World Action, 1996.

VIDAL, John. UN Surveys a world of endless' cities. The Guardian Weekly, p. 4, 26 Mar. 2010.

VIEIRA, José. Meninos nas ruas de Luanda: para ensinar a sonhar. Audácia, revista electrónica, Jul. 2002. <http://www.audacia.org/cgi-bin/quickregister/scripts/redirect.cgi?redirect=EEuVyEZpVVmsdqCxAn>. Acesso em: 15 Fev. 2009.

VIEIRA, José Luandino. Nosso Musseque. Luanda; Lisboa: Editorial Nzila; Editorial Caminho, 1961, 1962, 2003.

VIGNAUX, Georges. O demónio da classificação. Pensar, organizar. Lisboa: Instituto Piaget, 1999. WEBSDALE, Neil. Policing the poor. From slave plantation to public housing. Boston: Northeastern University Press, 2001. 